\title{
Multidrug-resistant tuberculosis in Uzbekistan: results of a nationwide survey, 2010 to 2011
}

D J Ulmasova1, G Uzakova², M N Tillyashayhov³, L Turaev4, W van Gemert55, H Hoffmann ${ }^{6}$, M Zignol5, K Kremer7, T Gombogaram ${ }^{8}$,

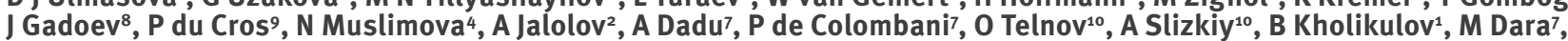

D Falzon (falzond@who.int) 5

1. Republican DOTS Centre, Tashkent, Uzbekistan

2. Programme Implementation Unit, The Global Fund to Fight AIDS, TB and Malaria (TGF), Tashkent, Uzbekistan

3. National Institute of TB and Pulmonology, Tashkent, Uzbekistan

4. National Reference Laboratory (NRL), Tashkent, Uzbekistan

5. World Health Organization, Global TB Programme, Geneva, Switzerland

6. Supranational TB Reference Laboratory (SRL Gauting), IML red GmbH, synlab Bayern, Asklepios Fachkliniken MünchenGauting, Germany

7. World Health Organization Regional Office for Europe, Copenhagen, Denmark

8. World Health Organization Country Office, Tashkent, Uzbekistan

9. Médecins Sans Frontières (MSF), London, United Kingdom

10. Médecins Sans Frontières (MSF), Tashkent/Nukus, Uzbekistan

Citation style for this article:

Ulmasova DJ, Uzakova G, Tillyashayhov MN, Turaev L, van Gemert W, Hoffmann H, Zignol M, Kremer K, Gombogaram T, Gadoev J, du Cros P, Muslimova N, Jalolov A, Dadu A, de Colombani P, Telnov O, Slizkiy A, Kholikulov B, Dara M, Falzon D. Multidrug-resistant tuberculosis in Uzbekistan: results of a nationwide survey, 2010 to 2011. Euro Surveill. 2013;18(42):pii=20609. Available online: http://www.eurosurveillance.org/ViewArticle.aspx?Articleld=20609

Article submitted on 30 January 2013 / published on 17 October 2013

Multidrug-resistant tuberculosis (MDR-TB; resistance to at least rifampicin and isoniazid) is a global public health concern. In 2010-2011, Uzbekistan, in central Asia, conducted its first countrywide survey to determine the prevalence of MDR-TB among TB patients. The proportion of MDR-TB among new and previously treated TB patients throughout the country was measured and risk factors for MDR-TB explored. A total of 1,037 patients were included. MDR-TB was detected in 165 treatment-naïve $(23.2 \%$; $95 \%$ confidence interval (CI) $17.8 \%-29.5 \%)$ and 207 previously treated $(62.0 \%$; $95 \% \mathrm{Cl}: 52.5 \%-70.7 \%)$ patients. In $5.3 \%(95 \% \mathrm{Cl}$ : $3.1 \%-8.4 \%$ ) of MDR-TB cases, resistance to fluoroquinolones and second-line injectable drugs (extensively drug resistant TB; XDR-TB) was detected. MDR-TB was significantly associated with age under 45 years (adjusted odds ratio: 2.24 ; $95 \% \mathrm{Cl}: 1.45-3.45$ ), imprisonment (1.93; $95 \% \mathrm{Cl}: 1.01-3.70)$, previous treatment $(4.45 ; 95 \% \mathrm{Cl}: 2.66-7.43)$, and not owning a home (1.79; 95\% Cl: 1.01-3.16). MDR-TB estimates for Uzbekistan are among the highest reported in former Soviet Union countries. Efforts to diagnose, treat and prevent spread of MDR-TB need scaling up.

\section{Introduction}

Tuberculosis (TB) remains a major challenge to public health worldwide. In 2011, the World Health Organization (WHO) estimated that there were about 12 million prevalent TB cases globally of whom about 630,000 were infected with strains resistant to at least both rifampicin and isoniazid (multidrug-resistant TB; MDR-TB) [1]. Inadequate use of anti-TB drugs to treat drug-susceptible TB favours the emergence of drug resistance. MDR-TB patients require combination treatment which commonly lasts 20 months or more, employing drugs which are difficult to procure and more toxic and expensive than those used to treat drug-susceptible forms of the disease [2-4].

Over the last decade, countries of the former Soviet Union have reported the highest levels of MDR-TB infection among TB patients $[5,6]$. In one of these countries, Uzbekistan, in central Asia, two sub-national studies performed since 2001 have detected MDR-TB in 13-15\% of new TB patients and in $40-60 \%$ of previously treated patients [7,8]. In 2011 Uzbekistan had a population of 29 million inhabitants and a Gross National Income of EUR 1,137 per capita, making it a lower middle income country [9]. The state Republican DOTS Centre (RDC) in the capital city Tashkent is responsible for the TB control services in all of the country's 14 administrative divisions, including the Autonomous Republic of Karakalpakstan. In 2011, Uzbekistan reported 15,913 TB cases, $28 \%$ of whom were culture-confirmed and $50 \%$ of these also had results for drug-susceptibility testing (DST) to both isoniazid and rifampicin [10].

As estimates from subnational surveys may not necessarily be generalisable to a whole country, the RDC conducted the first nationally-representative study of anti-TB drug resistance based on a countrywide sample of TB patients in Uzbekistan. The estimate from this study would enable the national TB control programme and its partners, particularly Médecins Sans Frontières (MSF) and the Global Fund against AIDS, TB and Malaria (TGF), to better target their efforts and resources and understand the different risk factors associated with MDR-TB, including co-infection with human immunodeficiency virus (HIV). In this article we describe the main outcomes of the survey and we 
discuss their implications for the continued surveillance, prevention, diagnosis, treatment and scale-up of MDR-TB programme management in the country. We believe the findings of this study are relevant beyond the country's borders as they add to the current knowledge base about the burden of MDR-TB in eastern Europe [11], a phenomenon that has a sizeable impact upon the epidemiology of TB in European Union countries as a result of migration and population movements [12].

\section{Methods}

Sampling, recruitment and statistical analysis The objectives of the study were to estimate (i) the proportion of new (TB treatment-naïve) and previously treated (four weeks of treatment or more) TB cases infected with MDR-TB strains; (ii) the proportion of MDR-TB cases infected with strains additionally resistant to fluoroquinolones and second-line injectable drugs (extensively drug-resistant TB; XDR-TB [13]); and (iii) the magnitude of association between risk factors and infection with MDR-TB strains. Definitions used for previous treatment history and resistance patterns were as recommended by WHO [14]. A detailed survey protocol including associated costs was prepared according to these WHO guidelines and approved by the National Ethics Committee of the Ministry of Health.

The survey was carried out using non-invasive techniques employed in the course of regular investigation of any patient with presumptive TB. Patients were asked to sign their informed consent for participation. Confidentiality was respected during collection and storage of clinical data.

The sampling frame consisted of pulmonary TB patients diagnosed at public healthcare facilities in all administrative regions of Uzbekistan. All patients diagnosed with positive sputum smear on microscopy were eligible for inclusion. The sample size was calculated on the basis of new sputum-smear TB cases notified in the country in $2008(n=5,234)$, an expected prevalence of $15 \%$ MDR-TB among new cases (based on the most recent survey in Tashkent) [8], an absolute precision of $2.5 \%$ of the expected prevalence, and a $95 \%$ confidence level. A total of 818 new cases were thus required, inclusive of a $20 \%$ margin to cover for expected losses. As all previously treated sputumsmear positive TB cases presenting to healthcare facilities during the survey period were also to be recruited, 1,174 study subjects were targeted in total.

The survey was carried out over the 12 months until June 2011 using 100\% sampling. The national sample was split among the different regions (Oblasts) according to the TB notification patterns from 2008. During the study period, eligible patients were referred from the districts to the regional-level TB dispensaries for enrolment, collection of sputa for the study and interviewing until the expected number of cases from each region was reached. Cases were excluded if they were sputum smear-positive at the end of a re-treatment regimen, or if sputum was collected 10 days or more into the current course of treatment, or if they did not or could not consent, or if they were not smear-positive, or were later found to be infected with strains other than Mycobacterium tuberculosis complex. All patients were offered HIV testing and counselling. A standardised information form was used to collect data (Figure 1). Information was cross-checked with patient records when available and then transferred from the completed forms onto two electronic registers housed at the National TB Reference Laboratory (NRL) and the RDC and then merged.

The proportions used to describe the first-line drug resistance patterns among new and previously treated cases tested were weighted by the TB cases notified in each administrative region in 2011. Univariate analysis was used to study relationships between risk factors and MDR-TB, and associations with p<0.10 were further analysed using multivariable logistic regression. Effects were expressed as crude and adjusted odds ratios and p<0.05 was considered statistically significant. The associations were further explored by imputing missing values and by using random-effects modelling. Statistical analysis was performed using STATA SE/12.1 (StataCorp LP, TX, USA) and the ggplot2 package running in the $R$ environment ( $R$ 3.0.1; [15]) was used to produce all graphics.

\section{Laboratory procedures}

The country is covered by a network of over 320 laboratories which perform direct microscopy of sputum at primary healthcare level. Two laboratories in the country can perform both culture and DST for first- and second-line anti-TB drugs reliably: the NRL in Tashkent and the laboratory at the TB hospital in Nukus, Karakalpakstan. Both laboratories perform DST on solid and liquid media, line-probe assay (LPA) and participate in quality assurance programmes with the WHO supranational TB reference laboratories (SRL) in Borstel and Gauting, Germany. Laboratory capacity to detect drug-resistance has increased substantially in Uzbekistan since 2008 and more than a thousand MDR-TB cases are now detected each year in the coun$\operatorname{try}[1]$.

For the purposes of the survey, 3 to $5 \mathrm{ml}$ of sputum were collected from each study participant. If inspection of the specimen showed saliva or insufficient quantity, the patient was asked to provide a morning sputum the following day. Patients whose sputum was found to be smear-positive at the district or regional level laboratories using bright-field microscopy after hot ZiehlNeelsen staining, were requested to provide a second sputum specimen. The second specimens were stored between $4^{\circ} \mathrm{C}$ and $12^{\circ} \mathrm{C}$ for a maximum of six days before shipment to the NRL in Tashkent where they were rechecked using fluorescence microscopy after Auramine 0 staining. Specimens from Karakalpakstan 
FIGURE 1

Clinical Information Forma ${ }^{\text {a }}$ nationwide study on drug-resistant tuberculosis, Uzbekistan, 2010-2011

\begin{tabular}{|c|c|c|c|}
\hline \multirow{9}{*}{$\begin{array}{l}\text { Part 1. Details of } \\
\text { the TB patient }\end{array}$} & 1. & DRS code & \\
\hline & 2. & Region & \\
\hline & 3. & District & \\
\hline & 4. & Patient surname & \\
\hline & 5. & Patient name & \\
\hline & 6. & Date of birth & day/month/year \\
\hline & 7. & Sex & male/female \\
\hline & 8. & Date of registration in the TB register & day/month/year \\
\hline & 9. & HIV status & \\
\hline \multirow{8}{*}{$\begin{array}{l}\text { Part 2. Clinical } \\
\text { information }\end{array}$} & 10. & Have you ever been treated for TB previously? & $\begin{array}{l}\text { No (if not, ask questions 11-16) } \\
\text { Yes (if yes, go to question 17) }\end{array}$ \\
\hline & 11. & How long have you been sick? & \\
\hline & 12. & Did you have the same symptoms prior to this episode? & \\
\hline & 13. & $\begin{array}{l}\text { Did you have other symptoms of lung disease prior to } \\
\text { this episode (haemoptysis, chest pain, cough)? }\end{array}$ & \\
\hline & 14. & Did you have sputum examination prior to this episode? & \\
\hline & 15. & $\begin{array}{l}\text { Did you ever take anti-TB drugs for more than one } \\
\text { month? }\end{array}$ & \\
\hline & 16. & Did you ever have injections for more than one month? & \\
\hline & 17. & $\begin{array}{l}\text { Did the patient remember previous treatment for TB } \\
\text { after these questions? }\end{array}$ & \\
\hline \multirow{3}{*}{$\begin{array}{l}\text { Part 3. Medical } \\
\text { records and the } \\
\text { final decision on } \\
\text { previous anti-TB } \\
\text { treatment }\end{array}$} & 18. & $\begin{array}{l}\text { After checking through the available medical files have } \\
\text { you discovered that the patient was registered for TB } \\
\text { treatment before? }\end{array}$ & $\begin{array}{l}\text { No } \\
\text { Yes } \\
\text { (If yes, number in the TBo3 register) }\end{array}$ \\
\hline & 19. & $\begin{array}{l}\text { Final decision taking into consideration the answers } \\
\text { of the patient on the standardised clinical history: Has } \\
\text { the patient been previously treated for TB for more } \\
\text { than one month? }\end{array}$ & $\begin{array}{l}\text { No (go to question 21) } \\
\text { Yes (go to question 20) } \\
\text { Unknown }\end{array}$ \\
\hline & 20. & If yes, what was the outcome of previous treatment? & $\begin{array}{l}\text { Cured/treatment completed } \\
\text { Failed new patient regimen using first-line drugs only } \\
\text { Failed retreatment regimen using first line drugs only } \\
\text { Failed regimen including second-line drugs } \\
\text { Defaulted } \\
\text { Other }\end{array}$ \\
\hline \multirow{12}{*}{$\begin{array}{l}\text { Part } 4 \text {. Social } \\
\text { determinants }\end{array}$} & 21. & Country of birth? & $\begin{array}{l}\text { Uzbekistan } \\
\text { Abroad (specify the country) }\end{array}$ \\
\hline & 22. & Your education (completed)? & $\begin{array}{l}\text { Higher (University) } \\
\text { Middle special (Technical college) } \\
\text { Secondary } \\
\text { Primary or lower }\end{array}$ \\
\hline & 23. & Your housing conditions? & $\begin{array}{l}\text { House (apartment) owned } \\
\text { House (apartment) rented } \\
\text { Dormitory } \\
\text { Homeless }\end{array}$ \\
\hline & 24. & How many people share your house? & Specify the number of persons \\
\hline & 25. & Your occupation? & $\begin{array}{l}\text { student } \\
\text { unemployed / looking for a job } \\
\text { invalid } \\
\text { retired } \\
\text { occupation (specify) }\end{array}$ \\
\hline & 26. & Have you been in prison in the last 10 years? & $\begin{array}{l}\text { No } \\
\text { Yes (specify the number of years) }\end{array}$ \\
\hline & 27. & Have you travelled abroad for work in the last 2 years? & $\begin{array}{l}\text { No } \\
\text { Yes (specify the country) }\end{array}$ \\
\hline & 28. & How often do you take alcohol? & $\begin{array}{l}\text { never } \\
\text { rarely } \\
\text { sometimes } \\
\text { often }\end{array}$ \\
\hline & 29. & Have you been smoking daily during the past 5 years? & $\begin{array}{l}\text { No } \\
\text { Yes }\end{array}$ \\
\hline & 30. & Have you taken any illicit drugs during the last month? & $\begin{array}{l}\text { No } \\
\text { Yes } \\
\text { If yes, which drug: }\end{array}$ \\
\hline & & & \\
\hline & 31. & Have you been in hospital in the last 10 years? & $\begin{array}{l}\text { If yes, } \\
\text { i. for how many weeks } \\
\text { ii. which hospital }\end{array}$ \\
\hline
\end{tabular}


Flowchart of patients included in the nationwide study on drug-resistant tuberculosis, Uzbekistan, 2010-2011

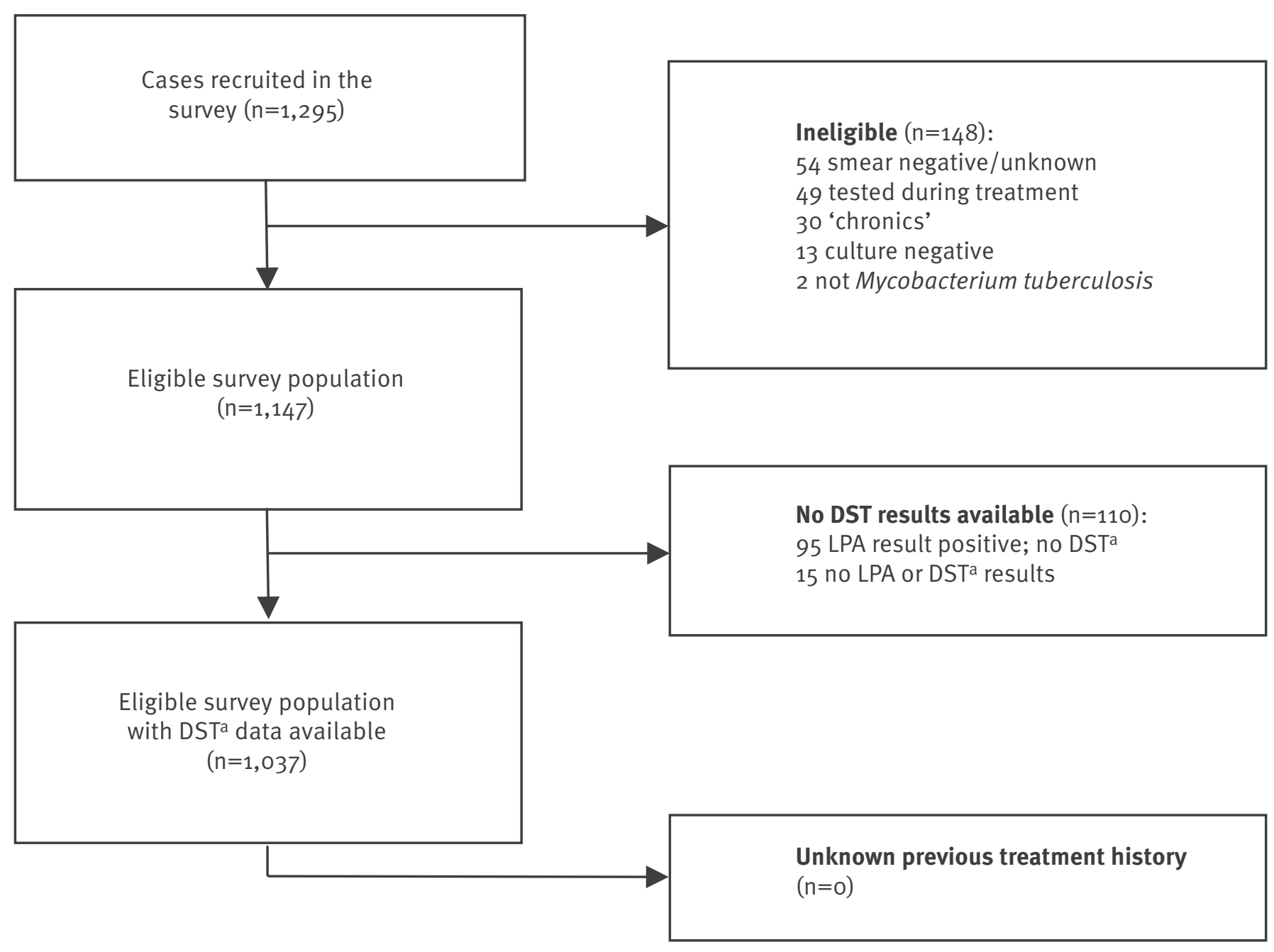

DST: drug-susceptibility testing; LPA: line-probe assay.

a For isoniazid and rifampicin (phenotypic).

and Khorezm were processed identically at the Nukus laboratory. Patients were considered smear-positive if at least one of two sputum specimens examined yielded $\geq 1$ acid fast bacillus per 100 high power fields [16]. All specimens were processed using a modified Petroff-method or NALC-NaOH procedures and inoculated in both Löwenstein-Jensen medium and mycobacteria growth indicator tube (MGIT) liquid medium (Becton-Dickinson, New Jersey, United States). DST was performed using the method of proportion [17] and the MGIT system. Susceptibility patterns to isoniazid, rifampicin, ethambutol and streptomycin were determined for all cases. If the growth of isolates allowed, MDR-TB strains were additionally tested for ofloxacin, a second-line aminoglycoside (amikacin and/or kanamycin) and capreomycin. Positive cultures were tested using Genotype MTBDRplus (1st generation, Hain Lifescience, Nehren, Germany) for identification of
M. tuberculosis complex and detection of resistanceconferring mutations to isoniazid and rifampicin. Each isolate, for which the results of genetic and phenotypic DST assays differed, was transferred to the SRL for determination of the final susceptibility pattern. If genetic mutations known to be associated with drug resistance were identified using Genotype MTBDRplus, the isolate was considered resistant to the respective drug. If no mutation was identified, the SRL repeated the DST in liquid medium and this result was considered definitive.

Quality control of DST was provided through (i) internal control according to EN DIN 58943-8:2009-04, (ii) four monitoring visits by an expert from the SRL München-Gauting (co-author H.H.), (iii) annual external quality assessment by testing a panel of 30 WHO control strains (provided by the Institute of Tropical 
Characteristics of the study population, completeness of drug-susceptibility testing data and associations with multidrugresistant tuberculosis in the nationwide study on drug-resistant tuberculosis, Uzbekistan, 2010-2011 ( $\mathrm{n}=1,037)$

\begin{tabular}{|c|c|c|c|c|c|c|c|c|c|c|c|c|}
\hline \multirow[t]{2}{*}{ Characteristic } & \multicolumn{2}{|c|}{ New } & \multicolumn{2}{|c|}{$\begin{array}{l}\text { Previously } \\
\text { treated }\end{array}$} & \multicolumn{2}{|c|}{ Total } & \multicolumn{2}{|c|}{$\begin{array}{l}\text { Missing } \\
\text { data for } \\
\text { DST }^{\mathrm{a}} \text { to } \\
\text { isoniazid } \\
\text { and } \\
\text { rifampicin }\end{array}$} & \multirow[t]{2}{*}{$\begin{array}{l}\text { Association } \\
\text { with } \\
\text { missingness, } \\
\text { Chi-square, } \\
\text { P-value }\end{array}$} & \multirow[t]{2}{*}{$\begin{array}{c}\text { MDR-TB, } \\
\%\end{array}$} & \multirow[t]{2}{*}{$\begin{array}{l}\text { Odds ratios } \\
\text { for MDR-TB, } \\
\text { univariate } \\
\text { analysis } \\
(95 \% \mathrm{Cls})\end{array}$} & \multirow[t]{2}{*}{$\begin{array}{l}\text { Adjusted } \\
\text { odds ratios } \\
\text { for MDR-TB, } \\
\text { multivariable } \\
\text { regression } \\
\text { (95\% Cls) }\end{array}$} \\
\hline & $\mathrm{n}$ & $\%$ & $\mathrm{n}$ & $\%$ & $\mathrm{n}$ & $\%^{b}$ & $n$ & $\%$ & & & & \\
\hline \multicolumn{13}{|l|}{ Sex } \\
\hline Female & 364 & 72 & 141 & 28 & 505 & 44 & 53 & 10 & \multirow{2}{*}{$0.85, P=0.36$} & 35 & Reference & NA \\
\hline Male & 418 & 65 & 224 & 35 & 642 & 56 & 57 & 9 & & 36 & $1.06(0.82-1.36)$ & NA \\
\hline \multicolumn{13}{|l|}{ Age } \\
\hline$>44$ years & 332 & 72 & 130 & 28 & 462 & 40 & 43 & 9 & \multirow{2}{*}{$0.07, P=0.79$} & 26 & Reference & Reference \\
\hline$<45$ years & 450 & 66 & 235 & 34 & 685 & 60 & 67 & 10 & & 43 & $2.11(1.61-2.76)$ & $2.24(1.45-3.45)$ \\
\hline
\end{tabular}

Administrative region/city

\begin{tabular}{|c|c|c|c|c|c|c|c|c|c|c|c|c|}
\hline Andijan & 81 & 82 & 18 & 18 & 99 & 9 & 2 & 2 & \multirow{14}{*}{$\begin{array}{l}185.9 \\
P=0.00\end{array}$} & 30 & Reference & Reference \\
\hline Bukhara & 22 & 55 & 18 & 45 & 40 & 3 & 0 & 0 & & 40 & $1.56(0.73-3.37)$ & $1.27(1.10-1.46)$ \\
\hline Djizak & 26 & 62 & 16 & 38 & 42 & 4 & 1 & 2 & & 37 & $1.35(0.63-2.92)$ & $1.05(0.80-1.39)$ \\
\hline Fergana & 109 & 87 & 16 & 13 & 125 & 11 & 16 & 13 & & 28 & $0.89(0.49-1.63)$ & $1.07(0.91-1.27)$ \\
\hline Karakalpakstan & 61 & 46 & 71 & 54 & 132 & 12 & 19 & 14 & & 62 & $3.82(2.14-6.80)$ & $2.33(1.85-2.94)$ \\
\hline Kashkadarya & 59 & 70 & 25 & 30 & 84 & 7 & 35 & 42 & & 51 & $2.44(1.20-4.96)$ & $2.17(1.60-2.95)$ \\
\hline Khorezm & 31 & 65 & 17 & 35 & 48 & 4 & 6 & 13 & & 33 & $1.17(0.54-2.54)$ & $0.73(0.60-0.89)$ \\
\hline Namangan & 63 & 73 & 23 & 27 & 86 & 7 & 9 & 10 & & 32 & $1.13(0.59-2.15)$ & $1.08(0.87-1.33)$ \\
\hline Navoiy & 17 & 44 & 22 & 56 & 39 & 3 & 1 & 3 & & 42 & $1.71(0.78-3.71)$ & $0.71(0.52-0.97)$ \\
\hline Samarkand & 96 & 77 & 28 & 23 & 124 & 11 & 1 & 1 & & 20 & $0.57(0.30-1.06)$ & $0.46(0.35-0.61)$ \\
\hline Surhadarya & 43 & 81 & 10 & 19 & 53 & 5 & 17 & 32 & & 17 & $0.47(0.18-1.25)$ & $0.44(0.34-0.56)$ \\
\hline Syrdarya & 32 & 68 & 15 & 32 & 47 & 4 & 0 & 0 & & 36 & $1.33(0.64-2.78)$ & $1.68(1.39-2.04)$ \\
\hline Tashkent city & 67 & 54 & 57 & 46 & 124 & 11 & 3 & 2 & & 38 & $1.44(0.81-2.54)$ & $0.93(0.79-1.09)$ \\
\hline Tashkent region & 75 & 72 & 29 & 28 & 104 & 9 & 0 & 0 & & 38 & $1.41(0.78-2.53)$ & $1.19(0.95-1.50)$ \\
\hline \multicolumn{13}{|l|}{ Origin } \\
\hline Uzbek & 764 & 68 & 360 & 32 & 1124 & 98 & 108 & 10 & \multirow{2}{*}{$0.02, P=0.88$} & 36 & Reference & NA \\
\hline Foreign & 18 & 78 & 5 & 22 & 23 & 2 & 2 & 9 & & 29 & $0.71(0.27-1.85)$ & NA \\
\hline \multicolumn{13}{|l|}{ Education } \\
\hline Higher & 242 & 66 & 125 & 34 & 367 & 32 & 24 & 7 & \multirow{2}{*}{$5.79, P=0.02$} & 38 & Reference & NA \\
\hline Up to secondary & 540 & 69 & 240 & 31 & 780 & 68 & 86 & 11 & & 35 & $0.85(0.65-1.10)$ & NA \\
\hline \multicolumn{13}{|l|}{ Home-owner } \\
\hline No & 102 & 63 & 59 & 37 & 161 & 14 & 22 & 14 & \multirow{2}{*}{$3.58, P=0.06$} & 43 & Reference & Reference \\
\hline Yes & 680 & 69 & 306 & 31 & 986 & 86 & 88 & 9 & & 35 & $0.70(0.49-1.01)$ & $0.56(0.32-0.99)$ \\
\hline \multicolumn{13}{|l|}{ Occupation } \\
\hline Not employed & 565 & 66 & 295 & 34 & 860 & 75 & 86 & 10 & \multirow[b]{2}{*}{$0.67, P=0.41$} & 38 & Reference & Reference \\
\hline $\begin{array}{l}\text { Employed/ } \\
\text { Student }\end{array}$ & 217 & 76 & 70 & 24 & 287 & 25 & 24 & 8 & & 30 & $0.72(0.53-0.97)$ & $0.67(0.37-1.22)$ \\
\hline \multicolumn{13}{|c|}{ In prison in the previous 10 years } \\
\hline No & 759 & 70 & 319 & 30 & 1078 & 94 & 106 & 10 & \multirow{2}{*}{$1.22, P=0.27$} & 34 & Reference & Reference \\
\hline Yes & 23 & 33 & 46 & 67 & 69 & 6 & 4 & 6 & & 60 & $2.88(1.72-4.81)$ & $1.93(1.01-3.70)$ \\
\hline \multicolumn{13}{|c|}{ Hospitalised in the last 10 years } \\
\hline No & 594 & 91 & 61 & 9 & 655 & 57 & 58 & 9 & \multirow{2}{*}{$0.95, P=0.33$} & 26 & Reference & Reference \\
\hline Yes & 188 & 38 & 304 & 62 & 492 & 43 & 52 & 11 & & 49 & $2.77(2.14-3.60)$ & $1.29(0.78-2.15)$ \\
\hline
\end{tabular}

CI: confidence interval; DST: drug-susceptibility testing; MDR-TB: multidrug-resistant tuberculosis; NA: not applicable.

a For isoniazid and rifampicin.

b For the column. 
Characteristics of the study population, completeness of drug-susceptibility testing data and associations with multidrugresistant tuberculosis in the nationwide study on drug-resistant tuberculosis, Uzbekistan, 2010-2011 (n=1,037)

\begin{tabular}{|c|c|c|c|c|c|c|c|c|c|c|c|c|}
\hline \multirow[t]{2}{*}{ Characteristic } & \multicolumn{2}{|c|}{ New } & \multicolumn{2}{|c|}{$\begin{array}{l}\text { Previously } \\
\text { treated }\end{array}$} & \multicolumn{2}{|c|}{ Total } & \multicolumn{2}{|c|}{$\begin{array}{l}\text { Missing } \\
\text { data for } \\
\text { DST }^{\mathrm{a}} \text { to } \\
\text { isoniazid } \\
\text { and } \\
\text { rifampicin }\end{array}$} & \multirow[t]{2}{*}{$\begin{array}{l}\text { Association } \\
\text { with } \\
\text { missingness, } \\
\text { Chi-square, } \\
\text { P-value }\end{array}$} & \multirow[t]{2}{*}{$\begin{array}{c}\text { MDR-TB, } \\
\%\end{array}$} & \multirow[t]{2}{*}{$\begin{array}{c}\text { Odds ratios } \\
\text { for MDR-TB, } \\
\text { univariate } \\
\text { analysis } \\
(95 \% \mathrm{Cls})\end{array}$} & \multirow[t]{2}{*}{$\begin{array}{l}\text { Adjusted } \\
\text { odds ratios } \\
\text { for MDR-TB, } \\
\text { multivariable } \\
\text { regression } \\
(95 \% \mathrm{Cls})\end{array}$} \\
\hline & $\mathrm{n}$ & $\%$ & $\mathrm{n}$ & $\%$ & $\mathrm{n}$ & $\%^{\mathrm{b}}$ & $\mathrm{n}$ & $\%$ & & & & \\
\hline \multicolumn{13}{|c|}{ Worked abroad in the last 2 years } \\
\hline No & 705 & 68 & 328 & 32 & 1033 & 90 & 95 & 9 & \multirow{2}{*}{$1.86, P=0.17$} & 36 & Reference & NA \\
\hline Yes & 77 & 68 & 37 & 32 & 114 & 10 & 15 & 13 & & 37 & $1.07(0.70-1.65)$ & NA \\
\hline \multicolumn{13}{|l|}{ Uses alcohol } \\
\hline Never & 480 & 70 & 206 & 30 & 686 & 60 & 67 & 10 & \multirow{2}{*}{$0.06, P=0.80$} & 36 & Reference & NA \\
\hline Yes & 302 & 66 & 159 & 34 & 461 & 40 & 43 & 9 & & 36 & $1.00(0.77-1.30)$ & NA \\
\hline \multicolumn{13}{|c|}{ Regular smoker } \\
\hline No & 640 & 71 & 268 & 29 & 908 & 79 & 99 & 11 & \multirow{2}{*}{$8.65, P=0.00$} & 35 & Reference & NA \\
\hline Yes & 142 & 59 & 97 & 41 & 239 & 21 & 11 & 5 & & 38 & $1.13(0.84-1.54)$ & NA \\
\hline \multicolumn{13}{|l|}{ HIV infection } \\
\hline No & 707 & 68 & 334 & 32 & 1041 & 91 & 106 & 10 & \multirow{3}{*}{$4.85, P=0.09$} & 32 & Reference & NA \\
\hline Yes & 18 & 55 & 15 & 45 & 33 & 3 & 2 & 6 & & 42 & $1.45(0.71-2.99)$ & NA \\
\hline Unknown & 57 & 78 & 16 & 22 & 73 & 6 & 2 & 3 & & 27 & $0.69(0.41-1.18)$ & NA \\
\hline \multicolumn{13}{|c|}{ Previously treated for TB } \\
\hline No & & & & & 782 & 68 & 77 & 10 & \multirow{2}{*}{$0.19, P=0.66$} & 23 & Reference & Reference \\
\hline Yes & & & & & 365 & 32 & 33 & 9 & & 62 & $5.42(4.09-7.19)$ & $4.45(2.66-7.43)$ \\
\hline
\end{tabular}

$\mathrm{CI}$ : confidence interval; DST: drug-susceptibility testing; HIV: human immunodeficiency virus; MDR-TB: multidrug-resistant tuberculosis; NA: not applicable.

a For isoniazid and rifampicin.

b For the column.

Medicine in Antwerp, Belgium), and (iv) re-checking by the SRL of a randomly-selected sample of all isolates collected for the survey. A total of 90 MDR-TB isolates, 104 fully susceptible ones, 102 isoniazid-resistant and rifampicin-susceptible ones, and two isoniazidsusceptible and rifampicin-resistant were rechecked using WHO-recommended sampling parameters (14). This control revealed $7 / 298(2.3 \%)$ errors for isoniazid, $3 / 298$ (1.0\%) for rifampicin, 0/90 (0\%) for ofloxacin, 6/90 (6.7\%), 4/90 (4.4\%) for kanamycin, and 5/90 (5.6\%) for capreomycin.

\section{Results}

A total of 1,147 eligible culture-positive cases remained in the study, after exclusion of ineligible cases included in the original dataset (Figure 2). The distribution of cases recruited in each of the administrative divisions in the country ranged from 3 to $12 \%$ of the total (Table 1). The ratio of new cases enrolled in the survey to those actually notified in each administrative region also varied, from $11.6 \%$ in Karakalpakstan to $28.3 \%$ in Syrdarya (Figure 3). The majority of cases were male $(642 ; 56 \%)$, under 45 years of age $(685$;
$60 \%)$, native Uzbeks $(1,124 ; 98 \%)$ and had not been previously treated $(782 ; 68 \%)$. Thirty-two percent of cases (367) had attended university or a technical college, $86 \%$ (986) lived in a home they owned, $25 \%$ (287) were employed or studying, $6 \%$ (69) had a history of imprisonment and 43\% (492) had been hospitalised in the previous 10 years. Intake of alcohol in the previous month was reported to be 'sometimes' or 'often' by $40 \%$ of patients (461), and $21 \%$ (239) had smoked regularly in the previous five years. HIV-infection was detected in $3 \%$ of cases (33).

Of the 1,147 cases, 1,037 (90\%) had DST results for all the four first-line drugs tested (isoniazid, rifampicin, ethambutol and streptomycin). Most cases with missing DST had a positive LPA test (95/110; 86\%), while in the rest no DST result could be traced. The availability of DST results did not differ significantly by the patient characteristics studied (Table 1).

\section{Resistance patterns by treatment history}

Table 2 shows the distribution of resistance to the four first-line drugs among new and previously treated 
patients for all 1,037 patients with DST results (percentages weighted for variations in notifications). Any resistance to one or more drugs was observed in $47 \%$ of new cases and $82 \%$ of previously treated, most often for isoniazid ( $42 \%$ in new and $79 \%$ in previously treated) or streptomycin ( $40 \%$ and $77 \%$ respectively). Most cases with rifampicin resistance were also resistant to the other three drugs (251/382) or to isoniazid and streptomycin (112), with only few cases (7) being mono-resistant to rifampicin. MDR-TB was detected in 372 cases $(23 \%$ of new and $62 \%$ of previously treated cases). The percentage MDR-TB in both new and previously treated cases did not vary significantly when the analysis was repeated after imputing data for the 110 cases with missing DST results. A total of 14 MDR-TB cases (3.8\%) were HIV-infected.

There were 319 MDR-TB cases (86\%) with DST results for at least one fluoroquinolone and one second-line injectable drug (Table 3). Of these, 17 (5.3\%; 95\% Cl $3.1 \%-8.4 \%)$ were resistant to both and thus XDR-TB. In addition, 23 cases (7.2\%) were resistant only to fluoroquinolones and another $63(19.7 \%)$ to second-line injectable drugs only. The prevalence of second-line drug resistance was comparable between new and previously treated cases. In 15 of 17 XDR-TB cases resistance was observed to all three second-line injectable drugs tested. None of the XDR-TB cases were HIV-infected.

\section{Risk factors associated with infection with MDR-TB strains}

At univariate analysis, significant positive associations with MDR-TB were observed with cases reported from Karakalpakstan and Kashkadarya (referenced to Andijan), age under 45 years, history of imprisonment or hospitalisation in the previous 10 years, and previous exposure to anti-TB treatment (Table 1). The percentage of MDR-TB was significantly higher in Karakalpakstan compared to Samarkand and Surhadarya, for new cases, and to Namangan for those previously treated (Figure 4).

When multivariable logistic regression was performed, MDR-TB was positively associated with age under 45

\section{FIGURE 3}

Ratio of new sputum-smear positive tuberculosis cases recruited in the survey ( $n=782$ ) to those notified in 2011, by administrative region, in the nationwide study on drug-resistant tuberculosis, Uzbekistan, 2010-2011

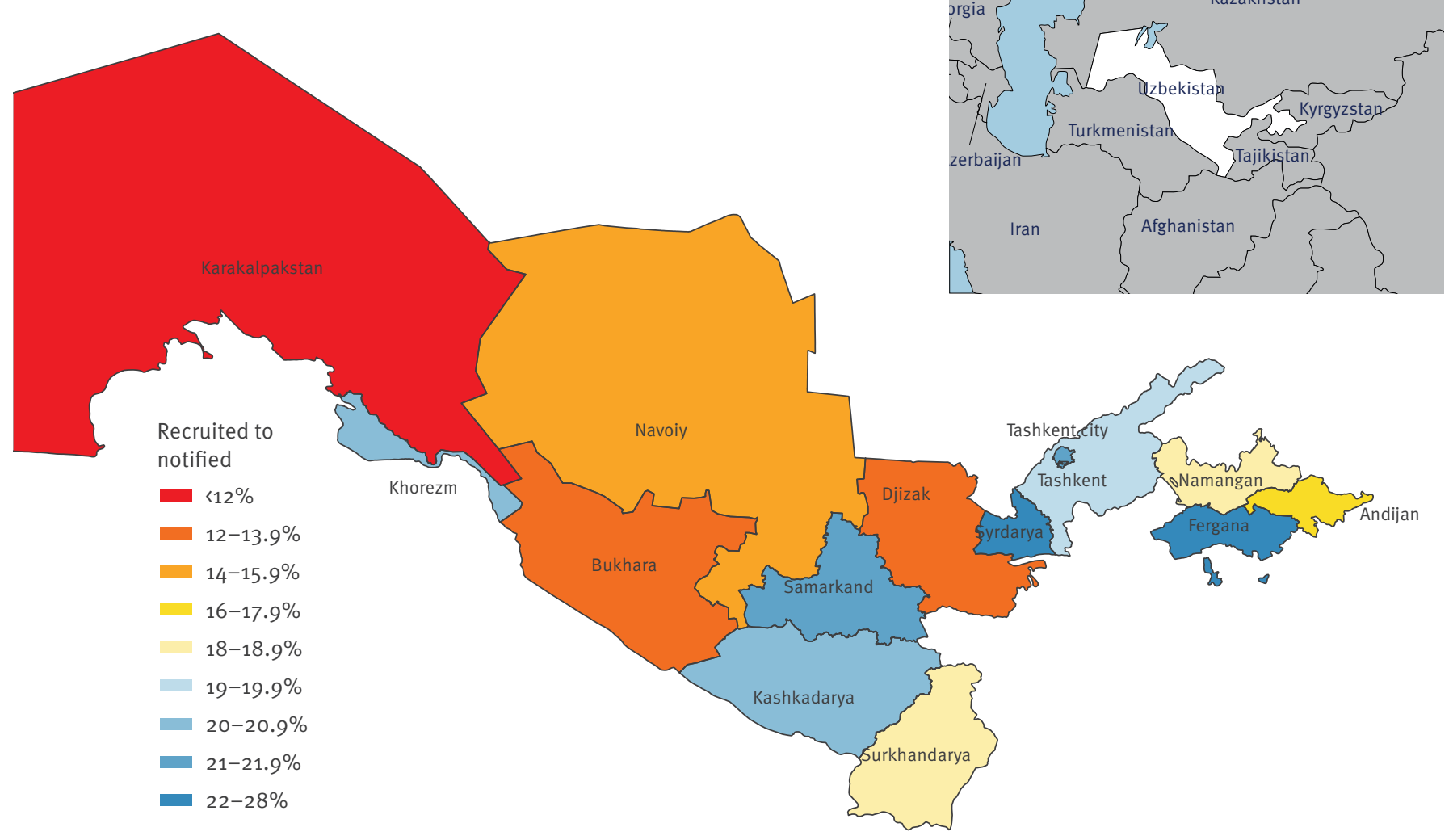


Drug-susceptibility results to first-line anti-tuberculosis drugs in the nationwide study on drug-resistant tuberculosis, Uzbekistan, 2010-2011 ( $\mathrm{n}=1,037)$

\begin{tabular}{|c|c|c|c|c|}
\hline \multirow{3}{*}{ Resistance pattern } & \multicolumn{4}{|c|}{ Treatment history ${ }^{\mathrm{a}}$} \\
\hline & \multicolumn{2}{|c|}{ New cases $(n=705)$} & \multicolumn{2}{|c|}{ Previously treated cases $(n=332)$} \\
\hline & $\%^{\mathrm{b}}$ & $95 \% \mathrm{Cls}^{\mathrm{b}}$ & $\%^{\mathrm{b}}$ & $95 \% \mathrm{Cls}^{\mathrm{b}}$ \\
\hline Any resistance to isoniazid $(\mathrm{H})$ & 41.9 & $(36.2-47.8)$ & 78.9 & $(70.4-85.5)$ \\
\hline Any resistance to rifampicin (R) & 24.2 & $(18.6-30.8)$ & 62.5 & $(53.0-71.1)$ \\
\hline Any resistance to ethambutol (E) & 20.1 & $(15 \cdot 6-25 \cdot 5)$ & 47.6 & $(39.9-55.4)$ \\
\hline Any resistance to streptomycin (S) & 40.0 & $(33.1-47.4)$ & 76.8 & $(65.9-85.0)$ \\
\hline Total any resistance & 47.4 & $(41.9-52.9)$ & 82.0 & $(71.6-89.1)$ \\
\hline Resistance to H only & 5.5 & $(3.3-8.9)$ & 3.4 & $(2.0-5 \cdot 7)$ \\
\hline Resistance to R only & 0.9 & $(0.4-1.7)$ & 0.2 & $(0.0-1.6)$ \\
\hline Resistance to E only & 0.0 & NA & 0.2 & $(0.0-2.0)$ \\
\hline Resistance to S only & 4.4 & $(2.5-7.5)$ & 2.0 & $(0.9-4.7)$ \\
\hline Total mono-resistance & 10.0 & $(7 \cdot 3-15 \cdot 5)$ & 5.8 & $(3.9-8.5)$ \\
\hline$H+R$ & 0.2 & $(0.0-1.4)$ & 0.9 & $(0.2-3 \cdot 4)$ \\
\hline$H+R+E$ & 0.3 & $(0.1-1.1)$ & 0.3 & $(0.1-2.3)$ \\
\hline$H+R+S$ & 6.9 & $(4.7-10.2)$ & 17.2 & $(11.4-25.1)$ \\
\hline$H+R+E+S$ & 15.8 & $(12.1-20.4)$ & 43.6 & $(36.4-51.2)$ \\
\hline Total multidrug resistance (MDR) & 23.2 & $(17.8-29.5)$ & 62.0 & $(52.5-70.7)$ \\
\hline$H+E$ & 0.6 & $(0.1-2.4)$ & 0.2 & $(0.0-1.9)$ \\
\hline $\mathrm{H}+\mathrm{S}$ & 9.3 & $(7.1-12.1)$ & 10.6 & $(8.5-13.2)$ \\
\hline$H+E+S$ & 3.4 & $(2.1-5.4)$ & 2.7 & $(1.1-6.4)$ \\
\hline$R+E$ & 0.0 & NA & 0.0 & NA \\
\hline$R+S$ & 0.2 & $(0.0-1.6)$ & 0.2 & $(0.0-1.5)$ \\
\hline$R+E+S$ & 0.0 & NA & 0.2 & $(0.0-2.0)$ \\
\hline$E+S$ & 0.1 & $(0.0-1.1)$ & 0.3 & $(0.1-2.1)$ \\
\hline Total poly-resistance other than MDR & 13.5 & $(10.6-17.1)$ & 14.2 & $(11.6-17.1)$ \\
\hline Total susceptible & 52.6 & $(47.1-58.1)$ & 18.0 & $(10.9-28.4)$ \\
\hline
\end{tabular}

$\mathrm{Cl}$ : confidence linterval; DRS: drug-resistance survey; E: ethambutol; H: isoniazid; MDR: multidrug resistance; NA: not applicable; $\mathrm{R}$ : rifampicin; S: streptomycin.

a Previous treatment history was known for all cases.

${ }^{b}$ Percentages have been weighted by the number of sputum-smear positive TB cases notified in each region in 2011.

years, not living in an owned home, history of imprisonment and previous anti-TB treatment. Regional variations in risk were also observed (Table 1 ).

\section{Discussion}

This is the first nationwide, representative anti-TB drug resistance survey of patients presenting for treatment in Uzbekistan. The proportion of new cases with MDR-TB calculated from this survey is higher than that found in other studies performed in parts of Uzbekistan since 2001. The estimate for MDR-TB in previously treated cases is similar to the one observed in the capital city Tashkent in 2005 [8] but higher than that in Karakalpakstan in 2001-2002 [7].

The proportion of MDR-TB among TB patients in Uzbekistan is among the highest being reported by former Soviet Union countries in recent years [11]. More than two-thirds of MDR-TB cases were resistant to ethambutol and therefore it is likely that in a majority of cases this drug will not be effective if it is added to a second-line drug regimen. HIV infection, which augurs badly for the prognosis in MDR-TB unless managed adequately, was infrequent. It is noteworthy that $44 \%$ 
Drug-susceptibility results to second-line anti-tuberculosis drugs, in the nationwide study on drug-resistant tuberculosis, Uzbekistan, 2010-2011 ( $\mathrm{n}=319)$

\begin{tabular}{|c|c|c|c|c|c|c|}
\hline \multirow{3}{*}{ Resistance pattern } & \multicolumn{6}{|c|}{ Treatment history $^{\mathrm{a}}$} \\
\hline & \multicolumn{3}{|c|}{ New MDR-TB cases } & \multicolumn{3}{|c|}{ Previously treated MDR-TB cases } \\
\hline & $\mathrm{n}$ & $\%$ & $95 \% \mathrm{Cls}$ & $\mathrm{n}$ & $\%$ & $95 \% \mathrm{Cls}$ \\
\hline $\begin{array}{l}\text { MDR-TB cases with DST results for any fluoroquinolone } \\
\text { and any second-line injectable drug }{ }^{\mathrm{b}}\end{array}$ & 144 & NA & NA & 175 & NA & NA \\
\hline $\begin{array}{l}\text { MDR-TB cases susceptible to both fluoroquinolones } \\
\text { and second-line injectable drugs }\end{array}$ & 99 & 68.8 & $60.5-76.2$ & 117 & 66.9 & $59.4-73.8$ \\
\hline MDR-TB cases with any resistance to fluoroquinolones & 11 & 7.6 & $3 \cdot 9-13 \cdot 3$ & 12 & 6.9 & $3.6-11.7$ \\
\hline $\begin{array}{l}\text { MDR-TB cases with any resistance } \\
\text { to a second-line injectable drug }\end{array}$ & 26 & 18.1 & $12.1-25 \cdot 3$ & 37 & 21.1 & $15 \cdot 3-27 \cdot 9$ \\
\hline $\begin{array}{l}\text { MDR-TB cases resistant to both a fluoroquinolone } \\
\text { and a second-line injectable drug (XDR-TB) }\end{array}$ & 8 & 5.6 & $2.4-10.7$ & 9 & 5.1 & $2.4-9.5$ \\
\hline
\end{tabular}

$\mathrm{Cl}$ : confidence interval; MDR-TB: multidrug-resistant tuberculosis; NA: not applicable; XDR-TB: extensively drug-resistant tuberculosis.

a Previous treatment history was known in all cases

b Cases tested for fluoroquinolones (one or more from ciprofloxacin, ofloxacin or moxifloxacin) and second-line injectable drugs (amikacin and/or kanamycin plus capreomycin; three cases had a test result for either amikacin/kanamycin or capreomycin only).

of MDR-TB cases detected in this survey were not previously exposed to anti-TB drugs and such cases were reported from all administrative regions. Two-fifths of new MDR-TB cases were in individuals aged between 13 and 30 years, with a male to female ratio of 1.2:1. Drugresistance in cases not previously exposed to anti-TB drugs generally indicates primary infection with resistant strains and points to shortfalls in prevention. Its widespread occurrence in our study across regions, ages and sexes implies that transmission probably occurs in different settings, such as hospitals, prisons, and households.

Representative surveillance data from a number of settings in the world indicate that on average $9.0 \%$ of MDR-TB cases (95\% Cl: 6.7-11.2) have XDR-TB strains [1]. Among MDR-TB patients in Uzbekistan, the proportion of XDR-TB was lower (5.3\%; 95\% CI: $3.1 \%-8.4 \%$ ) although the confidence interval overlaps with those of the global estimates. Nonetheless, two additional observations about the XDR-TB cases in this study have important inferences. Firstly, unlike the case with MDR-TB, the frequency of infection with XDR-TB strains was not different between new and previously treated MDR-TB patients. This indicates direct transmission of XDR-TB. Secondly, next to all XDR-TB patients were resistant to both classes of second-line injectable drugs, the aminoglycosides and the polypeptide capreomycin. This was higher than was found in a recent review [18]: it means that treatment options for XDR-TB patients are substantially compromised given that the injectable drugs - considered a mainstay of XDR-TB regimens [19] - are likely to be ineffective in most XDR-TB patients in the country.
Two social factors remained significantly associated with MDR-TB after adjustment: imprisonment and lack of home-ownership. Incarceration has been associated with MDR-TB elsewhere in the former Soviet Union [20]. This study has now documented this risk in a central Asian setting as well. Individuals who do not possess their house may be more prone to develop MDR-TB as a result of increased mobility and poor treatment adherence. In a subset analysis (data not shown), crude odds for MDR-TB were 1.5 times higher in unemployed patients when compared to those employed. Given that long-standing illness may reduce the chances of employment, this association may be in part an effect of MDR-TB rather than its cause.

Notifications of new sputum-positive TB cases in Uzbekistan have declined each year since 2006, from 7,211 that year to 4,198 in 2012 [1]. There is concern however, that this apparently promising trend may be accompanied by an increase in the prevalence of drug-resistant cases among the residual TB patients. In Uzbekistan, both drug-susceptible and drug-resistant TB patients have been treated in accordance with WHO-recommended guidelines for a number of years. DOTS first-line treatment regimens were piloted in the late 1990 s and expanded to reach nationwide coverage by 2005 . Since then, treatment success for new sputum-smear positive cases has been reported consistently at around $80 \%$, but is lower in previously treated cases [1].

All patients with MDR-TB detected in this survey were referred for treatment. In some sites, treatment could only be started when second-line drugs became available. Second-line drug treatment for MDR-TB patients is known to comply with international recommendations in 
Percentage of multidrug-resistance among new (left) and previously treated (right) tuberculosis cases by region/city in the nationwide study on drug-resistant tuberculosis, Uzbekistan, 2010-2011 ( $\mathrm{n}=1,037)$

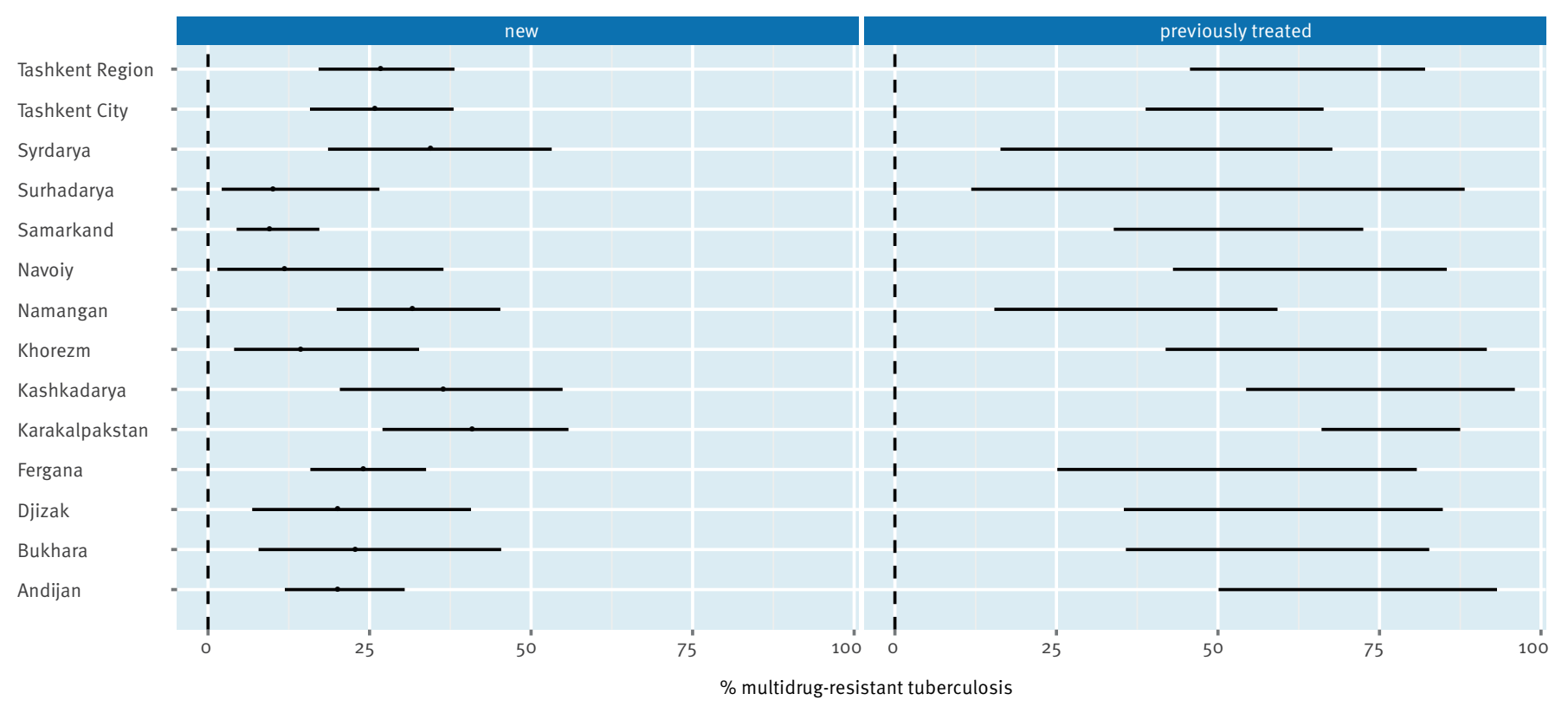

two treatment sites in Uzbekistan. In 2003, MSF started to support the treatment of drug-resistant TB patients in public healthcare facilities in a project approved by the Green Light Committee in Karakalpakstan [21]. Over 2,300 patients had started treatment by the end of April 2012 of whom over 900 were supported by funding from TGF. Among the 710 MDR-TB patients enrolled between 2003 and 2008, 62\% finished their treatment successfully [22]. In Tashkent, the RDC staff have been treating drug-resistant TB patients since 2006 through the support of TGF and UNITAID. By mid2012, 1,490 MDR-TB patients had started treatment and treatment success for the 446 patients enrolled in 2009 was $61 \%$. Treatment with second-line drugs is also available for imprisoned patients. In 2011, a total of 1,385 MDR-TB cases were detected in Uzbekistan, and 855 were enrolled on treatment. If the estimates observed in this survey are applied to the number of new and previously treated pulmonary TB cases notified in the country in 2011, about 3,000 MDR-TB cases (range: $2,700-3,400$ ) would be expected each year if DST were to be performed on all notified TB cases [1]. About $80 \%$ of these cases would be expected to occur among new TB patients. These numbers do not include prevalent MDR-TB cases surviving from previous years and who would likewise be eligible for treatment.

This study had some limitations. While the overall number of cases enrolled in the survey approached the target aimed for at the design stage, the number of cases recruited into the survey as a proportion of cases notified varied between the administrative regions. This may have under- or over-represented the contribution of cases from certain centres to the overall estimate. For this reason, the study estimates were weighted by the TB cases actually notified during the second year of the study (differences between weighted and unweighted values were small). The study was designed to estimate the proportion of MDR-TB among a nationwide sample of new TB cases and was not powered to detect differences between other patient subgroups or the administrative divisions in Uzbekistan. Thus, statistically significant differences could only be discerned between regions with extreme values. The proportion of MDR-TB among previously treated TB cases as estimated in this survey is expected to be conservative given that previously treated patients who experienced a treatment failure in a year prior to the one of the survey were not included.

The validity of data collected by patient interview alone on problem use of alcohol and narcotics was open to question and so these data were not used in the final analysis. This precluded the investigation of associations with these potential risks. The missing data on HIV status in $6 \%$ of patients may also have been the reason why no significant relationship was found between HIV infection and MDR-TB, an association which has been noted elsewhere in countries of the former Soviet Union [8]. Although data on DST were missing for 110 eligible cases, when the estimates were recalculated after imputation of missing values only slight differences were noted. The 'missingness' of DST data was therefore considered to be at random. Finally, as the study was limited to sputum-smear positive TB cases, it is possible that the patterns of resistance in children and in sputum-smear negative disease may differ from the ones described in this study. 
This survey has identified some useful leads for future study. Geographic disparities in MDR-TB levels may reflect confounding by social variables but also differences in programme performance and variations in the pattern of circulating strains. The lack of association with some of the risk factors measured may be in part due to problems with validity of data and also the relatively small number of observations. These require further study, particularly migration which has been linked to TB in recent reports in central Asia [23,24]. Migration from countries of the former Soviet Union to several European Union countries in the last decade has been marked [25], and studies such as the current one underline the importance of continued surveillance for drug-resistance in the western Europe $[12,26]$. Biochemical tests and expert interviewers may be needed to elicit valid answers to questions of a sensitive nature such as problem use of alcohol and narcotic drugs, lifestyles which have been associated with drug-resistant TB elsewhere in the former Soviet Union countries [27,28]. Genotyping studies may be required to identify any linked clusters of HIVassociated MDR-TB. Meta-analysis combining individual patient data from similar studies in other countries could usefully increase the power to detect associations and could add to the current evidence-base on the influence of specific drugs on successful outcome in MDR-TB and XDR-TB patients $[18,29]$.

In conclusion, the findings of this survey have an important bearing on the capacity of the national programme staff and their technical and financing partners to achieve universal access to adequate care for MDR-TB patients [30]. The implications are broad and point towards a need to expand ambulatory and inpatient facilities, the supply of second-line drugs, and safeguarding the quality of drugs [31]. Based on the findings of this study, and in line with Consolidated Action Plan to Prevent and Combat M/XDR-TB in WHO European Region 2011-2015 [32], Uzbekistan is implementing a national action plan to prevent and combat M/XDR-TB. Patient adherence to first-line drug treatment may need strengthening. Early detection of drugresistant $T B$ and institution of second-line treatment are crucial, as well as other infection control measures. The survey has served to improve the national laboratories' proficiency in undertaking culture and DST (first- and second-line) and LPA. The ongoing expansion in the use of LPA and Xpert MTB/RIF in Uzbekistan is expected to improve access for patient testing. Most cases with rifampicin resistance in this survey also had isoniazid resistance and therefore the positive predictive value of a rifampicin-resistant result for MDR-TB when using new rapid-diagnostic methods such as Xpert MTB/RIF is expected to be high [33].

Since 2011, five new laboratories in the country have acquired the capability to undertake good-quality culture and one more will be able to perform DST reliably shortly. This is expected to increase the patient coverage of DST in Uzbekistan, including the previously untreated TB patients who, as in many other countries, harbour a substantial part of the MDR-TB caseload [34]. If coupled with an efficient electronic system of data capture this would also enable the use of data from routine diagnostic testing for drug resistance surveillance in the near future. Finally, given that international migration is expected to keep increasing in the future, greater efforts to reinforce surveillance and response to the challenge of drug-resistant TB in countries such as Uzbekistan are expected to benefit public health beyond the confines of this country's border.

Acknowledgments

We thank Christopher Fitzpatrick of WHO for his support to the analysis of data.

The study was made possible by a grant of the TGF (Round 8), financial backing from WHO's Global TB Programme, and the time of staff from the Ministry of Health of Uzbekistan and WHO SRL Gauting. A Dadu, M Dara, P de Colombani, D Falzon, J Gadoev, K Kremer, G Tsogt, W van Gemert and M Zignol are all staff members of WHO and they alone are responsible for the views expressed in this publication and they do not necessarily represent the decisions or policies of WHO.

\section{Authors' contributions}

The survey was undertaken under the supervision of DJ Ulmasova, G Uzakova, H Hoffmann, L Turaev, MN Tillyashayhov, B Kholikulov, A Jalolov, N Muslimova, and J Gadoev. Technical advice on the study design and protocol were provided by W van Gemert, D Falzon, and M Zignol. P du Cros, K Kremer, A Dadu, P de Colombani, O.Telnov, A Slizkiy, $M$ Dara and G Tsogt also contributed to the analysis of the data. The writing of the manuscript was coordinated by $D$ Falzon and all the other co-authors provided substantive contributions to the content and format. All authors agree with the inferences and conclusions drawn.

\section{Conflicts of interest}

We declare that we have no conflicts of interest.

\section{References}

1. World Health Organization (WHO). Global Tuberculosis Report 2012. Geneva: WHO; 2012. Available from: http://apps.who.int/ iris/bitstream/10665/75938/1/9789241564502_eng.pdf

2. World Health Organization (WHO). Towards universal access to diagnosis and treatment of multidrug-resistant and extensively drug-resistant tuberculosis by 2015 . WHO progress report 2011. Geneva: WHO; 2011. Available from: http://whqlibdoc. who.int/publications/2011/9789241501330_eng.pdf

3. Falzon D, Jaramillo E, Schünemann HJ, Arentz M, Bauer M, Bayona J, et al. WHO guidelines for the programmatic management of drug-resistant tuberculosis: 2011 update. Eur Respir J. 2011;38(3):516-28. http://dx.doi. org/10.1183/09031936.00073611. PMid:21828024.

4. World Health Organization (WHO). Treatment of tuberculosis: guidelines. 4th ed. Geneva: WHO; 2009. Available from: http:// whqlibdoc.who.int/publications/2010/9789241547833_eng.pdf

5. World Health Organization (WHO). Multidrug and extensively drug-resistant TB (M/XDR-TB): 2010 global report on surveillance and response. Geneva: WHO; 2010. Available from: http://whqlibdoc.who.int/ publications/2010/9789241599191_eng.pdf 
6. Skrahina A, Hurevich H, Zalutskaya A, Sahalchyk E, Astrauko A, Hoffner S, et al. Multidrug-resistant tuberculosis in Belarus: the size of the problem and associated risk factors. Bull World Health Organ. 2013;91(1):36-45. http://dx.doi.org/10.2471/ BLT.12.104588. PMid:23397349. PMCid:PMC3537245.

7. Cox HS, Orozco JD, Male R, Ruesch-Gerdes S, Falzon D, Small I, et al. Multidrug-resistant tuberculosis in central Asia. Emerg Infect Dis. 2004;10(5):865-72. http://dx.doi.org/10.3201/ eid1005.030718. PMid:15200821. PMCid:PMC3323206.

8. World Health Organization (WHO). Anti-tuberculosis drug resistance in the world. Report No. 4. Geneva: WHO; 2008. Available from: http://whqlibdoc.who.int/hq/2008/who_htm_ tb_2008.394_eng.pdf

9. The World Bank. Uzbekistan. Washington: The World Bank. [Accessed 18 Jun 2013]. Available from: data.worldbank.org/ country/uzbekistan

10. European Centre for Disease Prevention and Control (ECDC) / World Health Organization (WHO) Regional Office for Europe. Tuberculosis surveillance and monitoring in Europe 2013. Stockholm: ECDC; 2013. Available from: http://www. ecdc.europa.eu/en/publications/Publications/Tuberculosissurveillance-monitoring-2013.pdf

11. Zignol M, van Gemert W, Falzon D, Sismanidis C, Glaziou P, Floyd K, et al. Surveillance of anti-tuberculosis drug resistance in the world: an updated analysis, 2007-2010. Bull World Health Organ. 2012;90(2):111-119D. http://dx.doi.org/10.2471/ BLT.11.092585. PMid:22423162. PMCid:PMC3302554.

12. Falzon D, Infuso A, Aït-Belghiti F. In the European Union, TB patients from former Soviet countries have a high risk of multidrug resistance. Int J Tuberc Lung Dis. 2006;10(9):954-8. PMid:16964783.

13. World Health Organization (WHO). WHO Global Task Force outlines measures to combat XDR-TB worldwide. Geneva: WHO; 17 Oct 2006. Available from: www.who.int/mediacentre/news/ notes/2006/np29/en/

14. World Health Organization (WHO). Guidelines for surveillance of drug resistance in tuberculosis. 4th ed. Geneva: WHO; 2009. Available from: http://whqlibdoc.who.int/ publications/2009/9789241598675_eng.pdf

15. The R Development Core Team. R: A language and environment for statistical computing. Vienna: R Foundation for Statistical Computing; 2013. Available from: http://cran.r-project.org/

16. World Health Organization (WHO). Seventh meeting of the Strategic and Technical Advisory Group for Tuberculosis (STAGTB). Report on conclusions and recommendations. Geneva: WHO; 2007. Available from: http://www.who.int/tb/events/ stag_report_2007.pdf

17. Canetti G, Fox W, Khomenko A, Mahler HT, Menon NK, Mitchison DA, et al. Advances in techniques of testing mycobacterial drug sensitivity, and the use of sensitivity tests in tuberculosis control programmes. Bull World Health Organ. 1969;41(1):21-43. PMid:5309084. PMCid:PMC 2427409.

18. Falzon D, Gandhi N, Migliori GB, Sotgiu G, Cox H, Holtz $\mathrm{TH}$, et al. Resistance to fluoroquinolones and secondline injectable drugs: impact on MDR-TB outcomes. Eur Respir J. 2013;42(1):156-68. http://dx.doi. org/10.1183/09031936.00134712. PMid:23100499.

19. World Health Organization (WHO). Guidelines for the programmatic management of drug-resistant tuberculosis, Emergency update 2008. Geneva: WHO; 2008. Available from: http://whqlibdoc.who.int/publications/2008/9789241547581_ eng.pdf

20. Kimerling ME, Kluge $H$, Vezhnina N, Iacovazzi T, Demeulenaere $\mathrm{T}$, Portaels F, et al. Inadequacy of the current WHO retreatment regimen in a central Siberian prison: treatment failure and MDR-TB. Int J Tuberc Lung Dis. 1999;3(5):451-3. PMid:10331736.

21. Cox HS, Kalon S, Allamuratova S, Sizaire V, Tigay ZN, RüschGerdes S, et al. Multidrug-resistant tuberculosis treatment outcomes in Karakalpakstan, Uzbekistan: treatment complexity and XDR-TB among treatment failures. PLoS One. 2007;2(11):e1126. http://dx.doi.org/10.1371/journal. pone.0001126. PMid:17987113. PMCid:PMC 2040509.

22. Lalor M, Allamuratova S, Tiegay Y, Khamraev A, Greig J, Braker $\mathrm{K}$, et al. Treatment outcomes in multidrug-resistant TB patients in Uzbekistan (Poster). 42nd Union World Conference on Lung Health. Lille, France; 2011.

23. Gilpin C, de Colombani P, Hasanova S, Sirodjiddinova U. Exploring TB-Related Knowledge, Attitude, Behaviour, and Practice among Migrant Workers in Tajikistan. Tuberc Res Treat. 2011: 548617. PMid:22567266. PMCid:PMC3335497.

24. Huffman SA, Veen J, Hennink MM, McFarland DA.

Exploitation, vulnerability to tuberculosis and access to treatment among Uzbek labor migrants in Kazakhstan. Soc Sci Med. 2012;74(6):864-72. http://dx.doi.org/10.1016/j. socscimed.2011.07.019. PMid:22094009.
25. Herm A. Population and social conditions. Statistics in Focus. 98/2008. Luxembourg: Eurostat Available from: http://epp. eurostat.ec.europa.eu/cache/ITY_OFFPUB/KS-SF-08-098/EN/ KS-SF-08-098-EN.PDF

26. Bernard C, Brossier F, Sougakoff W, Veziris N, Frechet-Jachym $\mathrm{M}$, Metivier N, et al. A surge of MDR and XDR tuberculosis in France among patients born in the Former Soviet Union. Euro Surveill. 2013;18(33):pii=20555. Available from: http:// www.eurosurveillance.org/ViewArticle.aspx?Articleld $=20555$. PMid:23968874.

27. Fleming MF, Krupitsky E, Tsoy M, Zvartau E, Brazhenko N, Jakubowiak W, et al. Alcohol and drug use disorders, HIV status and drug resistance in a sample of Russian TB patients. Int J Tuberc Lung Dis. 2006;10(5):565-70. PMid:16704041. PMCid:PMC1570181.

28. Mdivani N, Zangaladze E, Volkova N, Kourbatova E, Jibuti T, Shubladze N, et al. High Prevalence of Multidrug-Resistant Tuberculosis in Georgia. Int J Infect Dis. 2008;12(6):635-44. http://dx.doi.org/10.1016/j.ijid.2008.03.012. PMid:18514008. PMCid:PMC2645041.

29. Ahuja SD, Ashkin D, Avendano M, Banerjee R, Bauer M, Bayona JN, et al. Multidrug resistant pulmonary tuberculosis treatment regimens and patient outcomes: an individual patient data meta-analysis of 9,153 patients. PLoS Med. 2012;9(8):e1001300. http://dx.doi.org/10.1371/journal. pmed.1001300. PMid:22952439. PMCid:PMC3429397.

30. World Health Organization (WHO). Resolution WHA62.15. Prevention and control of multidrug-resistant tuberculosis and extensively drug-resistant tuberculosis. In: Sixty-second World Health Assembly, Geneva, 18-22 May 2009, Resolutions and decisions; annexes. Geneva: WHO; 2009. Available from: apps. who.int/gb/ebwha/pdf_files/WHA62-REC1/WHA62_REC1-en. pdf

31. World Health Organization (WHO). Survey of the quality of anti-tuberculosis medicines circulating in selected newly independent states of the former Soviet Union. Geneva: WHO; 2011. Available from: apps.who.int/medicinedocs/documents/ s19053en/s19053en.pdf

32. World Health Organization (WHO) Regional Office for Europe. Roadmap to prevent and combat drug-resistant tuberculosis. The Consolidated Action Plan to Prevent and Combat Multidrug- and Extensively Drug-Resistant Tuberculosis in the WHO European Region, 2011-2015. Copenhagen: WHO; 2011. Available from: www.euro.who.int/_data/assets/pdf_ file/0014/152015/e95786.pdf

33. World Health Organization (WHO). Rapid Implementation of the Xpert MTB/RIF diagnostic test. Technical and operational "How-to" Practical considerations. Geneva: WHO. 2011; Available from: whqlibdoc.who.int/ publications/2011/9789241501569_eng.pdf

34. Royce S, Falzon D, van Weezenbeek C, Dara M, Hyder K, Hopewell $P$, et al. Multidrug resistance in new tuberculosis patients: burden and implications. Int J Tuberc Lung Dis. 2013;17(4):511-3. http://dx.doi.org/10.5588/ijtld.12.0286. PMid:23485384. 